\title{
Effect of Diet Quality and Housing on Water Status in Sudanese Desert Sheep and Goats
}

\author{
Hashim Mohamed Elhadi* \\ Department of Physiology, Faculty of Veterinary Medicine, \\ University of Khartoum, Shambat, Sudan
}

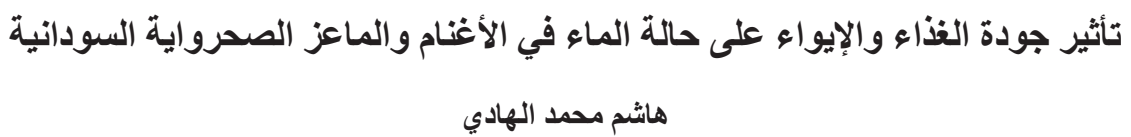

الخلاصة: تم إجـراء تجربتين منفصلتين استخدم فيهما الضأن الصحراوي والماءز في السودان لدراسة إيض الماء (مجموع الماء في الجسم ومعدل تحول الماء)

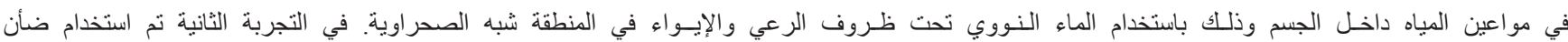

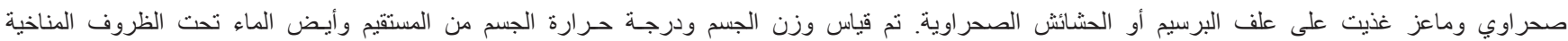

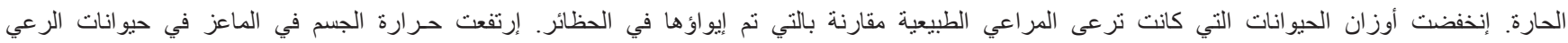

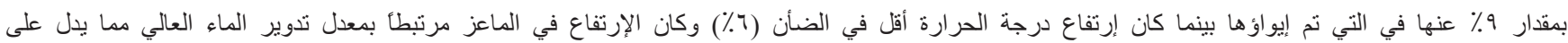

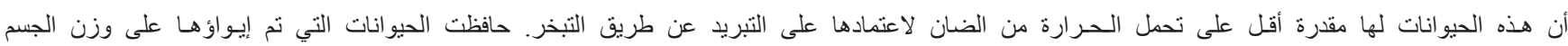

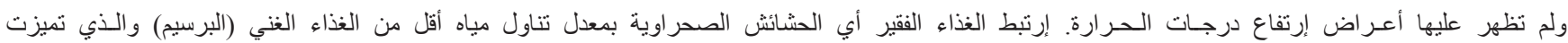

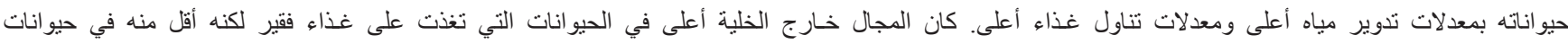
الرعي. كان المجال داخل الخلية أعلى في الحيو انات التي تغذت على البرسيم.

\begin{abstract}
Two independent experiments were carried out using Sudanese Desert sheep and goats to investigate water metabolism (total body water, TBW and water turnover, WTO) and internal water compartments using radioactive water (tritium), under natural grazing conditions in a semi-desert area. The second trial was carried out on confined sheep, fed high (Lucerne) and poor quality (desert grasses) diets. The body weights, rectal temperature and water parameters were monitored in both trials and species under the Sudanese summer conditions. The grazing animal's body weights were reduced compared to confined ones. Hyperthermia was pronounced in goats $(9 \%)$ compared to sheep (6\%). The goat hyperthermia was associated with high water turnover, indicating the poor heat tolerance of this species of high evaporative cooling. The confined animals, however, maintained their body weights and did not show signs of hyperthermia. The poor diet (desert grasses) was associated with reduced water intake whereas the Lucerne was associated with high water turnover and high feed intake. The extracelluar compartment (ECV) was higher with the poor diet but was lower than the grazing group. The intracellular compartment (ICV) was higher in the Lucerne group. The study indicated that Sudanese Desert sheep are more tolerant to high temperatures and grazing system than goats.
\end{abstract}

Keywords : Sudan, desert sheep, goats, water turnover, water space.

\section{Introduction}

The Sudan has an area of one million square miles; half of this area is desert or semi-desert in the north of the country. The average rainfall is less than $75 \mathrm{~mm}$ or from $75 \mathrm{~mm}$ to 300 $\mathrm{mm}$ annually, in the desert and semi desert respectably. In the desert, apart from a few shrubs and grasses which springup after the rare showers, it is almost devoid of vegetation. However, in the semi-desert areas, the rains are erratic and unreliable and confined to the months of July and August. The vegetation consists of grasses, herbs and a scattered variety of shrubs and bushes. In such arid and semi-arid areas, the maximum temperature exceeds $35^{\circ} \mathrm{C}$ and values of up of $46^{\circ} \mathrm{C}$ are not uncommon during May and June. The solar radiation reaches $550 \mathrm{cal} / \mathrm{m}^{2}$, however, the relative humidity is low, ranging from $10-30 \%$.
Under such conditions, a huge area is unsuitable to livestock. However, in areas where the livestock can survive, the bulk of the sheep and goat population is maintained under nomadic husbandry systems. The migration of nomads in pursuit of water and pasture may be up to $200 \mathrm{~km}$, while distances between grazing and watering points often exceed $40 \mathrm{~km}$. The watering interval is 3-7 days, however F.D Islander (personal communications) indicated that 11 days interval in sheep in winter, is not uncommon.

The ability of animals to survive, and indeed thrive under these harsh conditions, requires an extremely efficient adaptation, which may be reflected in their water usage and metabolism. 
There were approximately 51 million sheep and 43 million goats in the Sudan in 2007 (FAOSTAT, 2010). Desert sheep are the predominant breed in the country whereas the two major goat breeds are Desert goat and Nubian goat.

However, despite the considerable importance of both sheep and goats to the livestock industry in the Sudan, there is a lack of information concerning the water requirements and metabolism of these animals, such information is needed for successful implementation of the livestock developmental schemes in areas where water is at a premium.

\section{Materials and Methods}

\section{Approach}

The present study was an attempt to examine the water requirements and metabolism of sheep and goats, under the natural grazing and shaded confined conditions. The first trial was a comparison of the water and temperature parameters of sheep and goats under natural grazing practice in a semi-desert area about $10 \mathrm{~km}$ north of Khartoum.

The second trial involved the influence of dietary quality on water metabolism and body fluid volumes in sheep maintained under confined conditions. Their total body water (TBW) and water turnover (WTO) measurements were monitored using radioactive water (Tritium- ${ }^{3} \mathrm{H}$ ) and their relationship to their water intake, as measured by conventional methods.

\section{Animals}

In the first experiment, a total of 12 animals, comprising 6 desert rams, aged 2-3 years, and 6 Nubian bucks, aged 1-2 years, were used. The animals were kept in the semi-desert area (Latitude $15 \mathrm{~N}$ ) for 2 weeks before the investigation commenced. The meteorological data were collected by whirling hygrometer at 06:00, 13:00 and 17:00 hours, the mean air temperature was $20.3^{\circ} \mathrm{C}, 35.7^{\circ} \mathrm{C}$ and $33.5^{\circ} \mathrm{C}$, respectively. The relative humidity remained at $35 \%$ during the experimental period. Rectal temperatures of animals were measured using a clinical thermometer.

In the second experiment, twelve desert rams (weighing 23-34 kg) were divided into two groups, each group (6 sheep) was housed, in the semi-desert area, in two separate and similar semi -shaded pens. A period of 20 days was allowed for acclimatization to the feeding and watering regime followed by 10 days of collection period. Each group received either $6 \mathrm{~kg}$ of sun-dried chopped Lucerne

Table 1. Nutrient composition of lucerne hay and desert grass.

\begin{tabular}{lccccc}
\hline Diet & $\begin{array}{c}\text { DM } \\
(\%)\end{array}$ & $\begin{array}{c}\text { OM } \\
(\%)\end{array}$ & $\begin{array}{c}\text { CP } \\
(\%)\end{array}$ & $\begin{array}{c}\text { Ash } \\
(\%)\end{array}$ & $\begin{array}{c}\text { Energy Kcal/ } \\
\text { gm DM }\end{array}$ \\
\hline Lucerne Hay & 83 & 78.5 & 18.7 & 24.5 & 4.72 \\
Desert Grass & 94 & 85.4 & 3.4 & 8.7 & 4.12 \\
\hline
\end{tabular}

or $6 \mathrm{~kg}$ of dry desert grass. The compositions of both types are given in Table 1. The food and water are offered in the morning (06:00) and their refusal or orts were weighed at 17:00 hours to calculate the amount consumed.

\section{Water Parameters}

The total body water (TBW) was determined using tritiated water $\left({ }^{3} \mathrm{H}\right)$ and the dilution principle, the animals were injected at $5 \mathrm{pm}$ using $2 \mathrm{ml}$ of an isotonic solution of sodium chloride, containing $600 \mu$ ci (sheep) or $400 \mu$ ci (goats) given by deep intramuscular injection to each animal. The animals were then weighed; food and water were suspended till the following morning when the first blood sample was collected in heparinized tubes for radioassay. Subsequent blood samples were collected in the morning and evening for 10 days for the measurement of water turnover (WTO), plasma samples were prepared by adding $0.5 \mathrm{ml}$ to $10 \mathrm{ml}$ of "Instagel" (Packard) and tritium was assayed in a liquid scintillation spectrometer (Beckman). Similar measurements were made on the standard injected solution. The (TBW) was calculated by dividing the injected radioactivity by the plasma ${ }^{3} \mathrm{H}$ concentrations 12 hours after injection and WTO was calculated by regression analysis of the plasma activities.

Plasma volume was determined using Evans Blue dye $(0.4 \mathrm{mg} / \mathrm{kg})$ and ECV fluid volume was determined using (12 mg/kg) sodium thiocyanate. The ICV was calculated by difference (TBW- ECV) which included the rumen volume.

A computerized (t-test) programme was used to test the significance of paired varieties in some parameters.

\section{Results and Discussion}

\section{Experiment 1}

During the 2 weeks period, the body weight of the grazing animals decreased slightly. The desert grasses were sparse and the animals had to walk about $5 \mathrm{~km}$ to and from the grazing area. The mean body weights of sheep decreased form $33.5 \pm 2.2$ to $32.4 \pm 2.0 \mathrm{~kg}$, and that of the goats decreased form $17.5 \pm 1.2$ to $16.4 \pm 1.1 \mathrm{~kg}$. This reduction in body weights might indicate an adaptive feature which enables these desert animals to eat below maintenance requirements at such poor pastoral conditions. Similar findings in body solids changes were reported in grazing sheep (MacFarlane and Howard, 1970; Degen, 1977). The data in Table 2 indicated a diurnal variation in the body temperature of the grazing animals. Although both species experienced some degree of hyperthermia, associated with increased air temperature, this was greater in goats $(9 \%)$ compared to in sheep $(6 \%)$, indicating that goats are more predisposed to heat stress. The goat hyperthermia was associated with high water turnover (Table 3 ). The poor heat tolerance of the Nubian goats might be a reflection of the fact that this type of goat is not a true desert ruminant, as they are usually restricted to riverain and urban areas as milk producers. 
Table 2. Rectal temperature of grazing sheep and goats and confined sheep having Lucerne and desert grass (mean \pm S.E).

\begin{tabular}{|c|c|c|c|c|}
\hline \multirow{3}{*}{ Time of Day } & \multicolumn{4}{|c|}{ Rectal Temperature $\left({ }^{\circ} \mathrm{C}\right)$} \\
\hline & \multicolumn{2}{|c|}{ Grazing animals } & \multicolumn{2}{|c|}{ Confined sheep } \\
\hline & Goats & Sheep & Lucerne hay & Desert grass \\
\hline 06:00 & $37.1 \pm 0.1$ & $37.9 \pm 0.3$ & $37.3 \pm 0.2$ & $37.1 \pm 0.2$ \\
\hline 13:00 & $40.5 \pm 0.1$ & $40.3 \pm 0.2$ & $38.6 \pm 0.1$ & $38.4 \pm 0.2$ \\
\hline $17: 00$ & $39.6 \pm 0.2$ & $39.8 \pm 0.2$ & $38.1 \pm 0.1$ & $37.9 \pm 0.1$ \\
\hline
\end{tabular}

Table 3. TBW, WTO, water intake in grazing animals (sheep and goats) and confined sheep having Lucerne or desert grass (mean \pm S.E).

\begin{tabular}{lcccc}
\hline \multirow{2}{*}{ Parameter } & \multicolumn{2}{c}{ Grazing Animals } & \multicolumn{2}{c}{ Confined Sheep } \\
\cline { 2 - 5 } & Goats & Sheep & Lucerne hay & Desert grass \\
\hline Wt $(\mathrm{kg})$ & $17.5 \pm 1.2$ & $33.3 \pm 2.2$ & $30.4 \pm 1.9$ & $28.8 \pm 1.5$ \\
TBW\% & $75.8 \pm 3.0$ & $72.6 \pm 1.4$ & $71.9 \pm 1.9$ & $68.7 \pm 1.0$ \\
$\mathrm{~T}^{1 / 2}$ (day) & $5.2 \pm 0.5$ & $9.9 \pm 0.8$ & $5.0 \pm 0.2$ & $7.1 \pm 0.1$ \\
Water intake $\mathrm{ml} / \mathrm{kg}$ of B.Wt. or DM & $100 \pm 9.8$ & $49 \pm 4.3$ & $76.0 \pm 1.1$ & $57 \pm 1.2$ \\
consumed/day & $108 \pm 9.6$ & $53.0 \pm 15.6$ & $100 \pm 2.5$ & $66.0 \pm 3.8$ \\
WTO/kg of B.Wt. or DM consumed/day & $181 \pm 18.4$ & $100 \pm 11.1$ & $183 \pm 4.2$ & $120 \pm 6.4$ \\
WTO/ $0.82 \mathrm{~kg} / \mathrm{day}$ & & & & \\
\hline
\end{tabular}

Table 4. Body weight $(\mathrm{kg})$ and total body water (TBW) and its distribution in the body of grazing sheep and goats and in confined sheep having Lucerne day and desert grass (mean \pm S.E).

\begin{tabular}{|c|c|c|c|c|}
\hline \multirow{2}{*}{ Parameter } & \multicolumn{2}{|c|}{ Grazing Animals } & \multicolumn{2}{|c|}{ Confined Sheep } \\
\hline & Goats & Sheep & Lucerne hay & Desert grass \\
\hline Wt (kg) & $17.5 \pm 1.2$ & $33.3 \pm 2.2$ & $30.4 \pm 1.9$ & $28.8 \pm 1.5$ \\
\hline TBW (\%) & $75.8 \pm 3.0$ & $72.6 \pm 1.4$ & $71.9 \pm 1.9$ & $68.7 \pm 1.0$ \\
\hline $\mathrm{ECV}^{1}(\%) \quad(\mathrm{SCN}$ Space$)$ & $31.2 \pm 0.8$ & $28.1 \pm 1.8$ & $22.6 \pm 1.1$ & $26.2 \pm 3.4$ \\
\hline $\mathrm{PV}^{2}(\%)$ & $5.1 \pm 0.2$ & $5.0 \pm 0.3$ & $5.6 \pm 0.4$ & $4.7 \pm 0.6$ \\
\hline $\mathrm{ISV}^{3}(\%)$ & $26.1 \pm 0.9$ & $23.6 \pm 1.8$ & $17.0 \pm 1.2$ & $21.5 \pm 2.8$ \\
\hline $\mathrm{ICV}^{4 *}(\%)$ & $44.6 \pm 2.5$ & $44.5 \pm 1.6$ & $49.7 \pm 3.3$ & $41.7 \pm 4.0$ \\
\hline
\end{tabular}

${ }^{1}$ Extracellular volume. ${ }^{2}$ Plasma volume (T-1824 space). ${ }^{3}$ Interstitial volume.

${ }^{4 *}$ Intracellular volume. Rumen and digestive fluids are included in this space.

\section{Fluids Volume}

The findings of these measurements are given in Tables 3 and 4. TBW \% was $72.6 \pm 1.4$ and $75.8 \pm 3$ in sheep and goat, respectively. These values are slightly higher than the values reported by MacFarlane et al. (1972) for these ruminants in the Somali desert, using similar procedures. The relatively high value might be due to the 12-hours post injection samples; at this time of sampling, some losses of the isotope could have occurred, which may have resulted in the overestimation of TBW. Since equilibrium of ${ }^{3} \mathrm{H}$ could take 5-7 hours in this species, such losses were presumably greater in the goats, however, the difference between the two species was not significant. TBW $\%$ reported by Kamal et al. (1972) for Ossami rams and Nubian bucks were higher than our values. This difference might indicate a better adaptive performance of our ruminants. The WTO (ml/ kg 0.82 / day) was $100 \pm 11.1$ and $181 \pm 18.4$ in the sheep and goats respectively as shown in Table 3 . The goats turned over significantly more water than the sheep $(\mathrm{P}<0.01)$ and this was also reflected in the direct water intake. The difference in WTO rate might be due to the high degree of hyperthermia which was severe 
in the goats and is reflected in the high extracellular space in the goats $(31.2 \pm 02)$ compared to $(28.1 \pm 1.8)$ in the sheep. This is probably the result of more evaporative cooling in the goats, associated with high water turnover. Degen (1977), produced similar values for ECV \% $(28.6 \pm 1.09)$ in the grazing Awassi sheep at $32^{\circ} \mathrm{C}$. Both species maintained similar plasma volume (PV) of 5\% and intracellular volume (ICV) of $44 \%$. (Table 4 ).

\section{Effect of Feed Type}

The Lucerne-fed group consumed all the feed offered, while the desert grass group used to leave some of the feed. Two sheep, in the Lucerne group, suffered mild diarrhoea during the first few days of the investigation, while none of the desert-grass group showed any signs of digestive disturbances. This indicates that sheep which are normally raised under extensive management and used to dry grass feeding needed only a short time to adapt to the new diet. The Lucerne group consumed $1 \mathrm{~kg}$ of food $(0.83 \mathrm{~kg} \mathrm{DM} /$ animal $)$ and drank 2.2 liters of water, while the desert grass group consumed $0.7 \mathrm{~kg}$ of desert hay (0.66 kg DM / animal) and drank 1.6 liters of water. Both groups maintained their body weights over the period of two weeks, indicating that both diets satisfied their maintenance requirements, since the desert grass is of low nitrogen content (Table 1), it seems that these desert sheep retained more nitrogen in their bodies with a reduced amount of water intake compared to the high water consumption with the Lucerne diet.

Table 3, indicates that both groups had similar ${ }^{3} \mathrm{H}$ space TBW. However, the Lucerne group had significantly $(\mathrm{P}<0.01)$ higher WTO associated with higher intake, probably indicating higher nitrogen excretion by the kidneys. Previous reports indicated that water restriction improved the nitrogen retention in sheep (English, 1966; Topps and Elliot, 1967; Singh, More and Sahani 1976). It is more probable that the adaptive feature of the desert sheep is that more nitrogen is retained with reduced water intake. The distribution of the ${ }^{3} \mathrm{H}$ space (TBW) is shown in Table 4, the striking feature in these results is that the extracellular space is higher in the animals eating a poor diet (26.2 \pm 3.4$)$ compared to those on a rich diet (Lucerne) $(22.6 \pm 1.1)$. These findings are in agreement with that of MacFarlane et al (1959), who found high values in sheep with poor nutrition. Since these two groups of animals did not show a wide diurnal variation in their body temperature (Table 2), as did grazing sheep (Experiment
1), their ECV\% is lower than that of the grazing sheep (Table 4).

Both diet-groups had a similar plasma volume (PV). However, the intracellular volume (ICV) of the Lucerne group was $49.7 \%$ while that of grazing sheep was $44.5 \%$ (Table 4) which might indicate a large rumen space in the Lucerne group which consumed more feed in comparison to sheep having a poor diet; ICV\% is 41.7 (Table 4).

\section{References}

Degen, A.A. 1977. Fat-tailed Awassi and German Merino sheep under semi-arid conditions. Journal of Agricultural Science, Cambridge, 88:693-698.

English, P.B. 1966. Water and electrolytes balance in sheep. 1. External balance of water, sodium, potassium and chloride. Research in Veterinary Science 7:233267.

FAOSTAT. 2010. Food and Agriculture Organization of the United Nations Statistics. (http://faostat.fao.org/site/573/DesktopDefa ult.aspx?PageID=573\#ancor).

Kamal T.H., O, Shahata and I.M. ElBanna. 1972. Effect of heat and water restriction on water metabolism and body fluids compartments in farm animals. In: Proceedings of Symposium of Isotopes Studies on Physiology of Domestic Animals. 95-100 STI / PUB / 309, IAEA. Vienna.

Macfarlane, W.V., R.J.H., Morris, B. Howard and O.E. Budtz-oslen. 1959. Extra-cellular fluid distribution in Merino sheep. Australian Journal of Agricultural Research 10:269-286.

Macfarlane, W.V. and B. Howard, 1970. Water in the Physiological Ecology of Ruminants. In: Physiology of Digestion and Metabolism in Ruminants. A.T. Phillipson (Editor), 362-374. England. Oriel Press.

Macfarlane, W.V., B. Howard and G. M. O. Maloiy. 1972. Tritiated water in field studies of ruminants in Africa. In: Proceedings of Isotopes Studies on Physiology of Domestic Animals. p 83, STI / PUB / 309. IAEA. Vienna.

Singh, N.B., T. More and K.L. Sahni. 1976. The effect of water deprivation on food intake, nutrient digestibility and nitrogen retention in sheep. Journal of Agricultural Science, Cambridge, 86:431-433.

Topps, J. H. and R. C. Elliot. 1967. Partition of nitrogen in uterine of African sheep given a variety of low protein diet. Animal Production 9:219-227. 